\title{
Adsorptive Separation of Propylene and Propane on a Porous Metal-Organic Framework, Copper Trimesate
}

\author{
Ji Woong Yoon, ${ }^{\dagger, *}$ In Tae Jang, ${ }^{\dagger}$ Kwan-Young Lee, ${ }^{\ddagger}, *$ Young Kyu Hwang, ${ }^{\dagger}$ and Jong-San Chang ${ }^{\dagger, *}$ \\ ${ }^{\dagger}$ Catalysis Center for Molecular Engineering, Korea Research Institute of Chemical Technology, \\ P. O. Box 107, Yuseong, Daejeon 305-600, Korea. ${ }^{*}$ E-mail: jschang@krict.re.kr \\ ${ }^{\ddagger}$ Department of Chemical and Biological Engineering, Korea University, Seoul 136-701, Korea \\ "E-mail: kylee@korea.ac.kr \\ Received September 16, 2009, Accepted November 24, 2009
}

Key Words: MOF, Copper trimesate, Adsorption, Separation, Propylene

The separation of propane and propylene has been commercially performed by an energy-intensive distillation process at about $243 \mathrm{~K}$ and $0.3 \mathrm{MPa}$ in a column containing over 100 trays to achieve polymer-grade propylene due to the physicochemical similarities. ${ }^{1}$ Among several efforts to replace the conventional distillation process, adsorptive separation appears to be one of the promising short-term solutions as an alternative for providing the polymer-grade propylene. ${ }^{2}$ However, it is still a longcherished desire to develop effective adsorbents with high sorption capacities, high separation ratio and easy regenerability for this process in spite of a plenty of reports on porous adsorbents such as cationic zeolites, Ag-doped silica, etc. ${ }^{3-4}$ Metal-organic frameworks (MOFs) are currently of great interest and importance ${ }^{5-7}$ because they possess extremely high surface area and pore volume, well-ordered porous structures, large amount of metal elements in crystalline frameworks and chemical functionalities. These properties enable to apply for gas purification and separation of gas mixtures. ${ }^{8-9}$ A porous MOF, copper trimesate $\left(\left[\mathrm{Cu}_{3}(\mathrm{BTC})_{2}\left(\mathrm{H}_{2} \mathrm{O}\right)_{3}\right]_{\mathrm{n}}\right.$, denoted as $\mathrm{CuBTC}$ hereinafter $)$ known as HKUST- $1^{10}$ is one of the first robust metal-organic framework (MOF) materials with a microporous structure that is reminiscent of zeolite frameworks. ${ }^{11}$ This material forms face centered-cubic crystals that contain an intersecting three dimensional system of large square-shaped pores $(9 \times 9 \AA)$. Interestingly, $\mathrm{CuBTC}$ obtained from solvothermal synthesis was recently tested for the adsorptive separation of a propanepropylene mixture. ${ }^{12-13}$ However, the sorption results have shown only a limited separation efficiency in which a separation factor for propylene over propane is 2.0 at $313 \mathrm{~K}$ and $5 \mathrm{kPa}$. Recently, we have reported microwave synthesis of CuBTC as an efficient way to get high crystallinity and high BET surface area. ${ }^{14}$ The high porosity of the resulting CuBTC encourages us to confirm the possibility to enhance the sorption capacities of $\mathrm{C} 3$ hydrocarbons as well as the sorption affinity to propylene. This work aims to explore the adsorptive separation for propylene over propane with CuBTC, obtained by microwave synthesis, through single component adsorption isotherms as well as breakthrough experiments of propane-propylene mixtures.

\section{Results and Discussion}

Single component equilibrium adsorption isotherms of pro- pane and propylene on $\mathrm{CuBTC}(\mathrm{M} 1)$ at a temperature range in the range of $303 \mathrm{~K}$ and $353 \mathrm{~K}$ are compared in Figure 1. For propane adsorption, Langmuir-type isotherms known as type I according to the IUPAC classification are observed at lower adsorption temperatures, but the isotherm shape changes to type $\mathrm{V}$ with increasing the sorption temperature (Figure 1a). Type V isotherms are generally characteristic of weak adsorbentadsorbate interactions, causing small uptakes at low relative pressures. In contrast, for propylene adsorption the adsorbed amount sharply increases with pressure, indicating type I isotherms at all temperatures (Figure 1b). These isotherms exhibit a higher adsorbed amount of propylene than for propane in the whole pressure and temperature ranges investigated (Figure $1 \mathrm{c}$ and $1 \mathrm{~d})$. The higher sorption affinity to propylene at low pressures $(<50 \mathrm{kPa})$ can be attributed to strong interactions between propylene and the monolayer of specific sites on the CuBTC(M1).

To figure out the interaction of propane and propylene with the CuBTC(M1) adsorbent, the isosteric heats of adsorption as a function of adsorption loading were measured by applying the Clausius-Clapeyron equation ${ }^{15}$ to the respective adsorption isotherms recorded at five different temperatures. Figure 2 displays the isosteric heats of adsorption for two adsorbates. The isosteric heat of adsorption for propane is approximately $-35 \mathrm{~kJ} / \mathrm{mol}$ and does not change significantly with coverage except the value at $2 \mathrm{mmol} / \mathrm{g}$ loading. However, the isosteric heats of adsorption for propylene $(-43 \sim-49 \mathrm{~kJ} / \mathrm{mol})$ are obviously higher than those for propane in the whole range of adsorption loading, revealing a strong interaction of propylene with specific sites of the MOF framework. It is gradually decreased with increasing the adsorption loading, indicating the energetic heterogeneity of the adsorbent surface. The average values for propane and propylene are well consistent with those from Dual Site Sips model, ${ }^{16}$ but they are much higher than that $(-33 \mathrm{~kJ} / \mathrm{mol})$ in the literature ${ }^{12,17}$ and even higher than that $(-41.8 \mathrm{~kJ} / \mathrm{mol})$ reported for a commercial CuBTC (BASF, Basolite C300). ${ }^{13}$ This result reveals the enhanced sorption affinity to propylene in the present sample.

In order to verify the separation performance of the CuBTC (M1) adsorbent, binary adsorption was carried out in terms of breakthrough column experiments. Figure 3 shows the breakthrough curves of an equimolar mixture of propane and pro- 
(a)

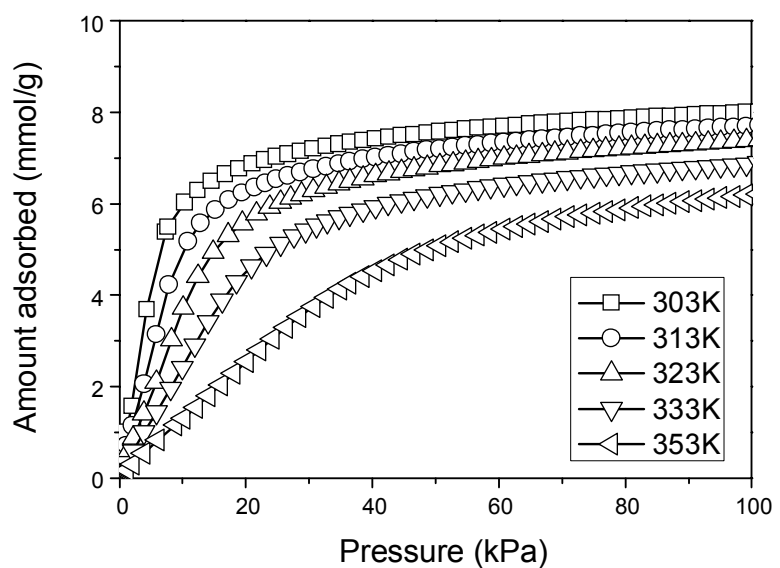

(c)

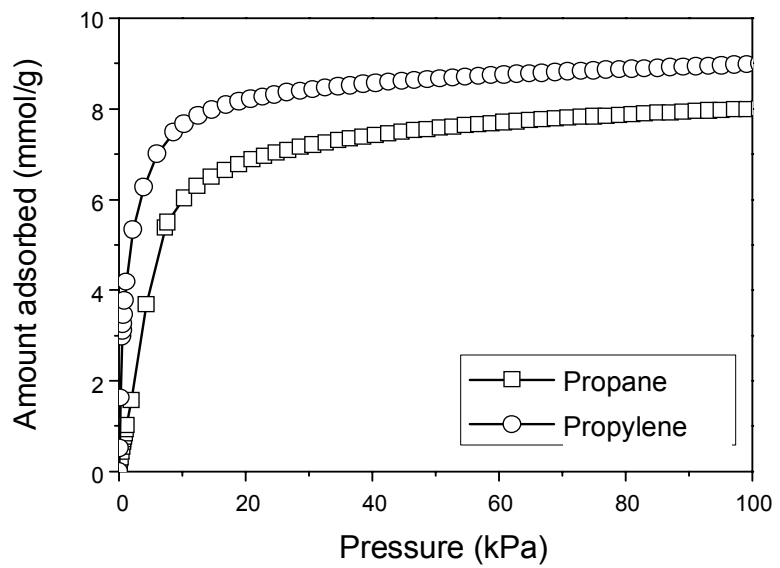

(b)

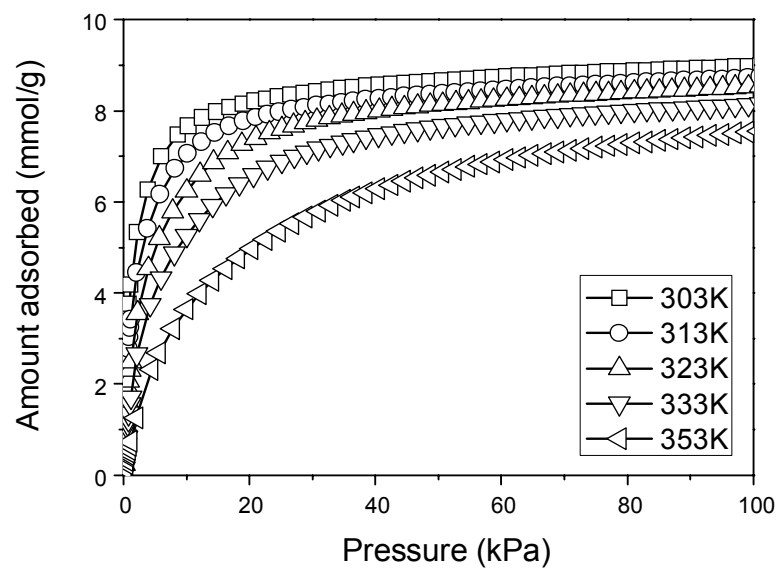

(d)

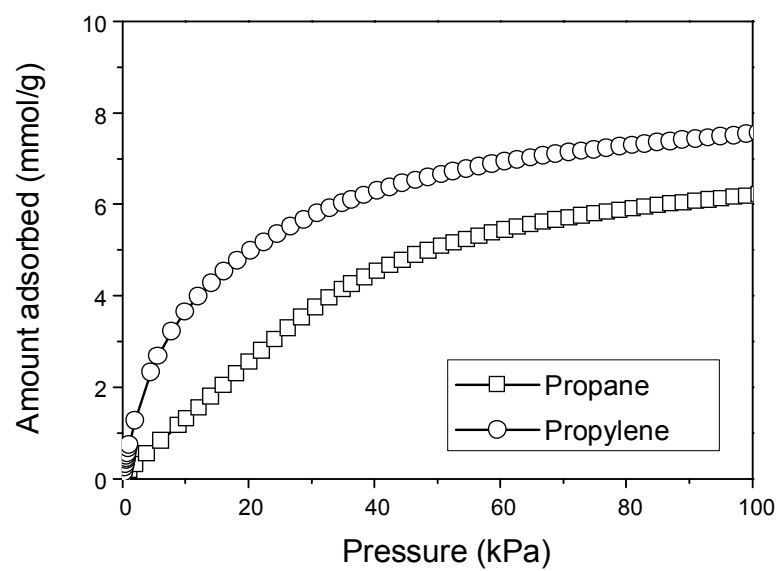

Figure 1. Single component adsorption isotherms of propane (a) and propylene (b) on CuBTC(M1) at different sorption temperatures ranging from $303 \mathrm{~K}$ to $353 \mathrm{~K}$. Comparison of adsorption isotherms of propane and propylene at $303 \mathrm{~K}$ (c) and at $353 \mathrm{~K}$ (d).

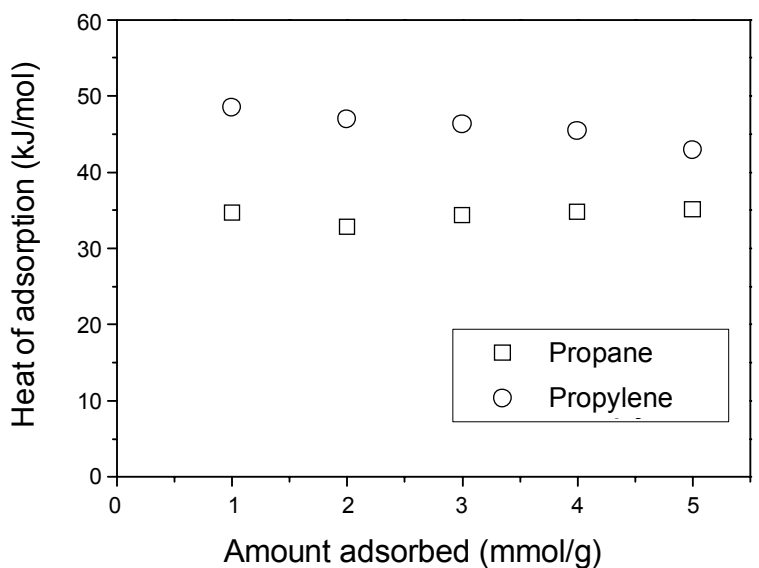

Figure 2. Isosteric heats of adsorption $\left(-\Delta \mathrm{H}_{\mathrm{ads}}\right)$ for propane and propylene on $\mathrm{CuBTC}(\mathrm{M} 1)$ according to adsorption loading between 1 and $5 \mathrm{mmol} / \mathrm{g}$.

pylene in helium $(2.5: 2.5: 95)$ at $313 \mathrm{~K}$. The adsorbent fully adsorbs two adsorbate molecules until $20 \mathrm{~min}$ and after then it does not adsorb propane any more in the continuous flow of the binary gas mixture. This means that propane free of propylene in the outlet of the column is obtained between 20 and $60 \mathrm{~min}$ because propylene appears in the gas flow from about $60 \mathrm{~min}$. It is noted that the partial pressure of propane exceeds its feed pressure of $2.5 \mathrm{kPa}$. This overshoot, so-called a 'roll-up' behavior, ${ }^{18}$ can be rationalized by two reasons. One is due to the change of gas composition from the equimolar binary gas mixture to a mixture containing only propane in helium because of occurrence of the complete adsorption of propylene. The other is due to a partial substitution of the weaker adsorbed propane by propylene on the adsorption sites. In other words, the adsorbed propane on the adsorption sites is readily displaced by the stronger adsorptive propylene in the gas mixture. The resulting desorption of propane leads to a further rise of the partial pressure in the outlet of the column. The roll-up is a result of preferential adsorption of propylene over propane. Figure 3 also illustrates the separation factors $(\alpha)$ of propylene over propane calculated by integration of areas in the breakthrough curves. These factors range from 3.3 (at $313 \mathrm{~K}$ ) to 5.5 (at $353 \mathrm{~K}$ ) depending on the operation temperature. These values are about 1.6 times higher than the reported one $(\alpha=2.0$ at $313 \mathrm{~K}$ ) at the same condition. ${ }^{13}$ Interestingly, the separation factors obtained from the breakthrough experiments are distinctively higher than those $(\alpha=2.4$ at $313 \mathrm{~K}$ and 3.7 at $353 \mathrm{~K})$ from equilibrium adsorption uptakes of each component at the same conditions. The discrepancy of the separation factors between sorption breakthroughs and equilibrium adsorption isotherms is ascribed to the presence of "roll-up" in the breakthrough curves of propane as mentioned above. 
(a)

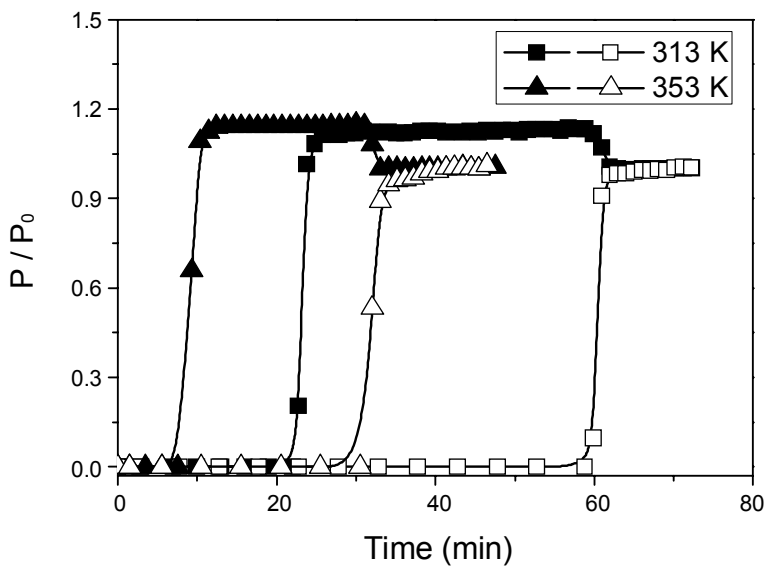

(b)

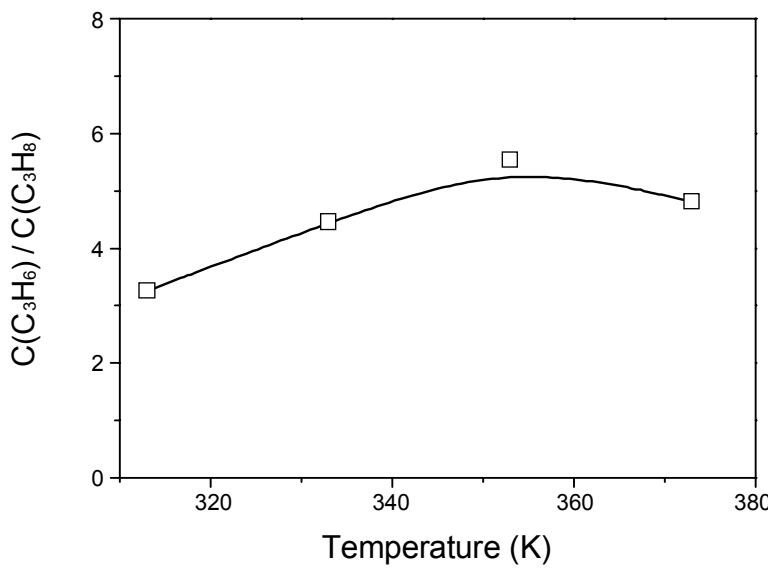

Figure 3. (a) Breakthrough curves (closed symbols: propane, blank symbols: propylene) and (b) separation factors, $\left[\alpha=\mathrm{C}\left(\mathrm{C}_{3} \mathrm{H}_{6}\right) / \mathrm{C}\left(\mathrm{C}_{3} \mathrm{H}_{8}\right)\right]$ in separation of an equimolar propane-propylene mixture in helium $(2.5: 2.5: 95)$ on $\mathrm{CuBTC}(\mathrm{M} 1)$ at different temperatures in the range of $303 \mathrm{~K}$ and $353 \mathrm{~K}$. Notation: $\mathrm{P}_{0}$, initial feed pressure; $\mathrm{P}$, outlet pressure; $\mathrm{C}\left(\mathrm{C}_{3} \mathrm{H}_{6}\right)$, the adsorbed molar amount of propylene; $\mathrm{C}\left(\mathrm{C}_{3} \mathrm{H}_{8}\right)$, the adsorbed molar amount of propane.

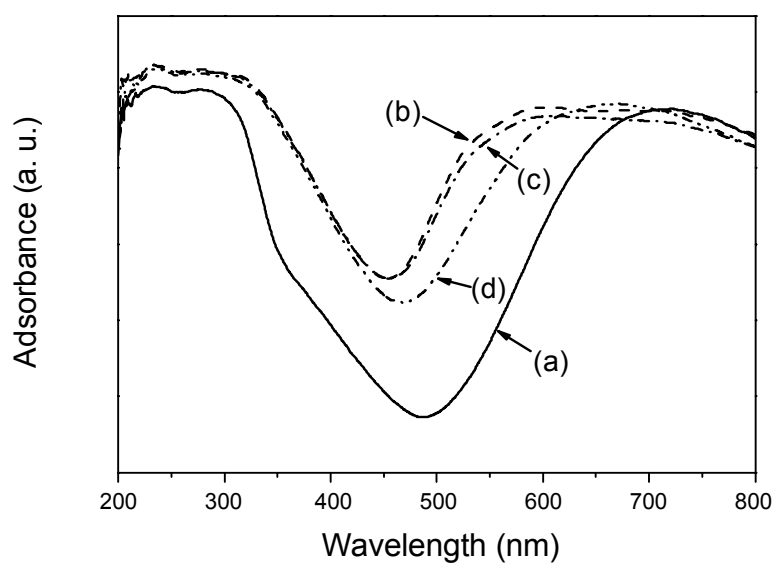

Figure 4. UV-Vis diffuse reflectance spectra of CuBTC(M1) according to hydration, dehydration and adsorption of propane and propylene: (a) hydration at $298 \mathrm{~K}$, (b) evacuation at $423 \mathrm{~K}$ followed by adsorption of (c) propane or (d) propylene at $298 \mathrm{~K}$.

In $\mathrm{CuBTC}$, the terminal axial water ligands are directed from the $\mathrm{Cu}$ atoms to the interior of the nanopores..$^{10}$ The free coordination $\mathrm{Cu}(\mathrm{II})$ sites formed upon dehydration are oriented towards the center of one of the larger pore types. UV-Vis spectral analyses were carried out to elucidate the interaction of propylene with the coordinatively unsaturated site (CUS) at the copper centers in CuBTC(M1). As illustrated in Figure 4, UV-Vis spectra show characteristic absorption bands due to ligand to metal charge transfer (LMCT) from oxygen to divalent copper ions at around $300 \mathrm{~nm}$ and a band centered at about $840 \mathrm{~nm}$ due to a d-d transition of octahedral $\mathrm{Cu}$ (II) ions in the hydrated sample. After evacuation of the sample at $423 \mathrm{~K}$, the LMCT and d-d bands become very broad because shoulders in both LMCT and d-d bands appear due to the change of degeneracy by departure of water molecule which is coordinated on a copper dimer. ${ }^{19}$ This indicates the formation of CUS Cu(II) ions in the dehydrated sample. The high-energy shoulder in the $\mathrm{d}-\mathrm{d}$ band is centered at around $540 \mathrm{~nm}$. The adsorption of propane on the dehydrated one at $298 \mathrm{~K}$ does not nearly change the UV-Vis spectrum, indicating a weak interaction between propane and copper sites. However, upon the adsorption of propylene the d-d band is shifted to lower energy showing the absorption maxima between 580 and $660 \mathrm{~nm}$. This bathochromic shift points to a strong interaction of propylene with CUS $\mathrm{Cu}(\mathrm{II})$ in the sample, resulting from an interaction between $\pi$-bonding orbital in propylene molecules with the vacant s-orbital of the copper ion in the CuBTC lattice. ${ }^{20}$

Table 1 summarizes physicochemical properties of several CuBTC samples including sorption uptakes for two adsorbates. CuBTC(M1) has the higher sorption uptakes of propane and propylene as compared with those of other samples from the literature. Reasonably, equilibrium sorption capacities of propane and propylene are closely related to their BET surface areas and porosities. However, the high separation factor for propylene is ascribed to an increase of specific sorption sites for propylene instead of porosity. Such sorption sites are just the free coordination $\mathrm{Cu}$ (II) sites formed upon dehydration as shown in UV-Vis spectra. The high surface area and high crystallinity led to increasing the concentration of strongly interacted sites with propylene in the dehydration sample, resulting in the high heats of adsorption for propylene. This result highlights the importance of synthesis and purification methods for MOFs that are utilized as adsorbents for selective sorption.

\section{Conclusion}

CuBTC prepared by the microwave method presented the high sorption affinity to propylene and the high isosteric heat of adsorption for propylene. UV-Vis spectra of CuBTC(M1) evidenced a strong interaction of the free coordination $\mathrm{Cu}(\mathrm{II})$ sites with propylene but a weak interaction with propane. These properties led to the high separation factor of propylene over propane in the binary gas mixture. These sorption data offers the potential to apply for the adsorptive separation of olefin and paraffin with CuBTC.

\section{Experimental Section}

Three different samples of CuBTC were chosen to test adsorptive sorption experiments for propane and propylene. 
Table 1. Physicochemical and sorption properties of various copper trimesates

\begin{tabular}{|c|c|c|c|c|c|c|c|}
\hline Adsorbent & $\mathrm{S}_{\mathrm{BET}}^{a}\left(\mathrm{~m}^{2} / \mathrm{g}\right)$ & $\mathrm{V}_{\text {pore }}^{a}(\mathrm{~mL} / \mathrm{g})$ & $\begin{array}{l}\text { Heating } \\
\text { method }^{b}\end{array}$ & $\begin{array}{l}\mathrm{Q}\left(\mathrm{C}_{3} \mathrm{H}_{8}\right)^{c} \\
(\mathrm{mmol} / \mathrm{g})\end{array}$ & $\begin{array}{l}\mathrm{Q}\left(\mathrm{C}_{3} \mathrm{H}_{6}\right)^{c} \\
(\mathrm{mmol} / \mathrm{g})\end{array}$ & $\begin{array}{l}\text { Separation } \\
\text { factor }^{d}\end{array}$ & Reference \\
\hline CuBTC(M1) & 1650 & 0.63 & MW & 7.72 & 8.75 & 3.3 & This work \\
\hline CuBTC(M2) & 1390 & 0.53 & MW & 6.58 & 7.71 & 2.8 & This work \\
\hline $\mathrm{Cu}_{3}(\mathrm{BTC})_{2}{ }^{e}$ & 1560 & 0.61 & - & 6.82 & 8.05 & 2.9 & [3], This work \\
\hline $\mathrm{Cu}_{3}(\mathrm{BTC})_{2}$ & 850 & - & $\mathrm{CE}$ & 2.80 & 3.25 & 2.0 & {$[7]$} \\
\hline
\end{tabular}

${ }^{a} \mathrm{~S}_{\mathrm{BET}}$ : BET surface area; $\mathrm{V}_{\text {pore }}$ : micropore volume. ${ }^{b} \mathrm{MW}$ : microwave heating; CE: conventional electrical heating. ${ }^{c}$ Equilibrium sorption uptakes of propane and propylene at $313 \mathrm{~K}$ and $101 \mathrm{kPa} .{ }^{d}$ The separation factors of propylene over propane obtained from breakthrough curves in the equimolar mixture of propylene over propane at $313 \mathrm{~K}$ and $5 \mathrm{kPa} .{ }^{e} \mathrm{~A}$ commercial adsorbent purchased from Sigma-Aldrich in a powder form (BASF, Basolite C300).

Two of them were prepared by the microwave method that has been reported elsewhere. ${ }^{14}$ The first sample obtained by microwave method using ethanol as a solvent at $413 \mathrm{~K}$ for 30 min is denoted as CuBTC(M1). The second sample denoted as CuBTC(M2) was obtained by the identical method except using an equimolar solvent mixture of water and ethanol. The third sample was purchased from SigmaAldrich in a powder form (BASF, Basolite C300). The BET analyses of three CuBTC samples were performed with $\mathrm{N}_{2}$ sorption isotherms at $77 \mathrm{~K}$ after dehydration under vacuum at $423 \mathrm{~K}$ for $12 \mathrm{~h}$ by using Micromeritics Tristar 3020. The UV-Vis diffuse reflectance spectra were obtained with propane and propylene adsorption at room temperature after dehydration under vacuum at $423 \mathrm{~K}$ for $12 \mathrm{~h}$ using Shimadzu UV-2501PC spectrophotometer, equipped with a reflectance sphere. The adsorption experiments were conducted with propane (99.95\%, Rigas corp.) and propylene (99.95\%, Rigas corp.) at 303 - $353 \mathrm{~K}$ (using water bath) after dehydration under vacuum at $423 \mathrm{~K}$ for $12 \mathrm{~h}$ by using Micromeritics Tristar 3000 . The breakthrough curves were performed in a fixed-bed flow system apparatus under atmospheric pressure. Before the breakthrough experiments, the CuBTC powders were palletized (below $50 \mathrm{~kg}_{\mathrm{f}} / \mathrm{cm}^{2}$ ), crushed, and sieved to obtain particles size between 0.3 and $0.5 \mathrm{~mm}$. After pelletization, the sample $(0.5 \mathrm{~g})$ was activated at $423 \mathrm{~K}$ with helium $(100 \mathrm{~mL} / \mathrm{min})$. The equimolar gas mixture of propane $(p=2.5$ $\mathrm{kPa})$ and propylene $(p=2.5 \mathrm{kPa})$ in helium $(30 \mathrm{~mL} / \mathrm{min})$ was used for the experiments. The outlet gases of the breakthrough column were analyzed on-line by gas chromatography using a flame ionization detector (FID).

Acknowledgments. This work was supported by the National Research Foundation of Korea (KN-0947) funded by Ministry of Education, Science and Technology. The authors thank Dr. Dong Won Hwang for helpful discussion and You-Kyong Seo for optimization of the synthesis recipe.

\section{References}

1. Eldridge, R. B. Ind. Eng. Chem. Res. 1993, 32, 2208.

2. Kumar, R.; Golden, T. C.; White, T. R.; Rokicki, A. Sep. Tech. $1992,15,2157$.

3. Peterson, D. L.; Helfferich, F.; Griep, R. K. in: Molecular Sieves p 217-229 Proc. $1^{\text {st }}$ Int. Conf. On Molecular Sieves, London 1967 published by Soc. for Chem. Ind. in 1968.

4. Gilliland, E. R.; Bliss, H. L.; Kip, C. E. J. Am. Chem. Soc. 1941, 63, 2088 .

5. Yaghi, O. M.; O'Keeffe, M.; Ockwig, N. W.; Chae, H. K.; Eddaoudi, M.; Kim, J. Nature 2003, 423, 705.

6. Férey, G.; Mellot-Draznieks, C.; Serre, C.; Millange, F.; Dutour, J.; Surblé, S.; Margiolaki, I. Science 2005, 309, 2040.

7. Hwang, Y. K.; Hong, D.-Y.; Chang, J.-S.; Jhung, S. H.; Seo, Y.-K.; Kim, J.; Vimont, A.; Daturi, M.; Serre, C.; Férey, G. Angew. Chem., Int. Ed. 2008, 47, 4144.

8. Eddaoudi, M.; Kim, J.; Rosi, N.; Vodak, D.; Wachter, J.; O’Keeffe, M.; Yaghi, O. M. Science 2002, 295, 469.

9. Kitagawa, S.; Kitaura, R.; Noro, S.-I. Angew. Chem., Int. Ed. 2004, 43, 2334.

10. Chui, S. S.-Y.; Lo, S. M.-F.; Charmant, J. P. H.; Orpen, A. G.; Williams, I. D. Science 1999, 283, 1148.

11. Pan, L.; Olson, D. H.; Ciemnolonski, L. R.; Heddy, R.; Li, J. Angew. Chem., Int. Ed. 2006, 45, 616.

12. Wagener, A.; Schindler, M.; Rudolphi, F.; Ernst, S. Chem. Ing. Tech. 2007, 79, 851 .

13. Lamia, N.; Jorge, M.; Granato, M. A.; Almeida Paz, F. A.; Chevreau, H.; Rodrigues, A. E. Chem. Eng. Sci. 2009, 64, 3246.

14. Seo, Y.-K.; Hundal, G.; Jang, I. T.; Hwang, Y. K.; Jun, C.-H.; Chang, J.-S. Microp. Mesop. Mater. 2009, 119, 331.

15. Thomas, J. M.; Thomas, W. J. Introduction to the Principles of Heterogeneous Catalysis; Academic Press: New York, 1967; p 102.

16. Chmelik, C.; Kärger, J.; Wiebcke, M.; Caro, J.; Van Baten, J. M.; Krishna, R. Micropor. Mesopor. Mater. 2009, 117, 22

17. Wagener, A.; Rudolphi, F.; Schindler, M.; Ernst, S. Chem. Ing. Tech. 2006, 78, 1328.

18. Yang, R. T. Gas Separation by Adsorption Process; ButterworthHeinemann: Stoneham, MA, 1987; p 173.

19. Prestipino, C.; Regli, L.; Vitillo, J. G.; Bonino, F.; Damin, A.; Lanberti, C.; Zecchina, A.; Solari, P. L.; Kongshaug, K. O.; Bordiga, S. Chem. Mater. 2006, 18, 1337.

20. Chen, N.; Yang, R. T. Ind. Eng. Chem. Res. 1996, 35, 4020. 